\title{
DAMAGE TOLERANCE EVALUATION OF WING IN PRESENCE OF LARGE LANDING GEAR CUTOUT THROUGH STRESS ANALYSIS USING FEM
}

\author{
Madhura B $M^{1}$, N.G.S. Udupa ${ }^{2}$, Rajanna $S^{3}$ \\ ${ }^{1}$ Nagarjuna College of Engineering and Technologies, Bangalore, Karnataka, India \\ ${ }^{2}$ Nagarjuna College of Engineering and Technologies, Bangalore, Karnataka, India \\ ${ }^{3}$ Govt. Engineering College, Kushalanagar, Karnataka, India
}

\begin{abstract}
Aircraft is symbol of a high performance mechanical structure, which has the ability to fly with a very high structural safety record. Aircraft experiences variable loading in service. Rarely an aircraft will fail due to a static overload during its service life. For the continued airworthiness of an aircraft during its entire economic service life, fatigue and damage tolerance design, analysis, testing and service experience correlation play a pivotal role. The present study includes the stress analysis and damage tolerance evaluation of the wing through a stiffened panel of the bottom skin with a landing gear cutout. Wing bottom skin experiences tensile stress field during flight. Cutouts required for fuel access and landing gear opening and retraction in the bottom skin will introduce stress concentration. Fatigue cracks will initiate from high tensile stress locations. An integral stiffened panel consisting a landing gear cutout is considered for the analysis. Stress analysis will identify the maximum tensile stress location in the panel. In a metallic structure fatigue manifests itself in the form of a crack which propagates. If the crack in a critical location goes unnoticed it could lead to a catastrophic failure of the airframe. A critical condition will occur when the stress intensity factor (SIF) at the crack tip becomes equal to fracture toughness of the material. SIF calculations will be carried out for a crack with incremental crack lengths using MVCCI method. Analytical evaluation of the crack arrest capability of the stiffening members ahead of the crack tip will be carried out.
\end{abstract}

Index Terms: Key Aircraft, Design, wing, landing gear cutout, stress analysis, FEM, damage tolerance, integral stiffened panel.

\section{INTRODUCTION}

1.1Some major parts of an aircraft are shown in the below figure.

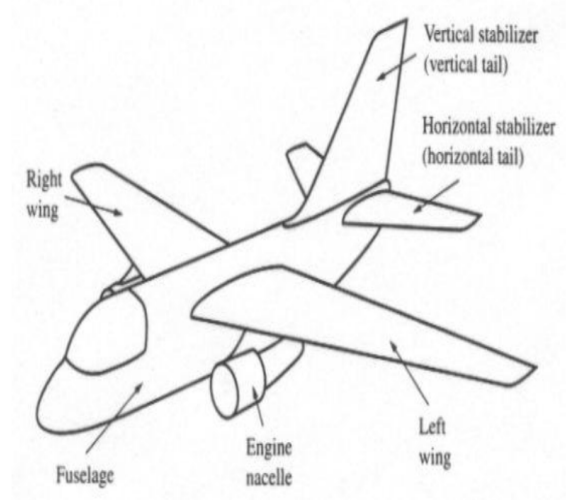

Fig -1: Important parts of an aircraft

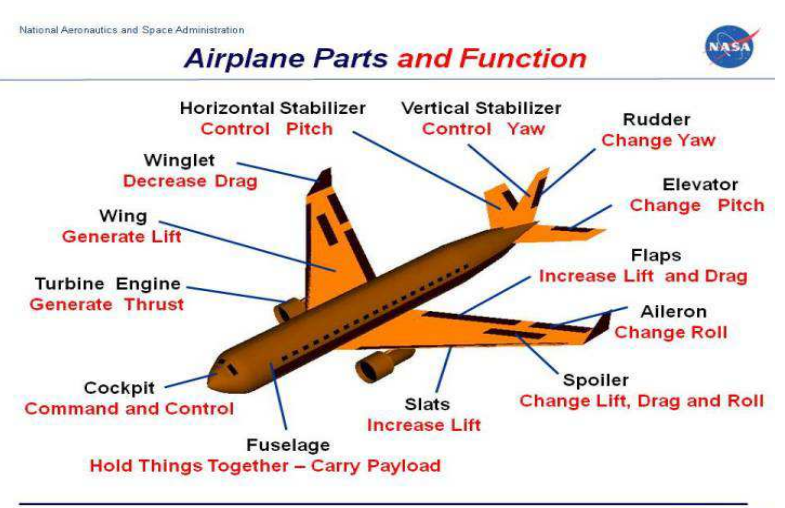

Fig -2: Airplane Parts and Functions

\subsection{Wings}

Providing lift is the main function of the wings of an aircraft. An aircraft wing is shown in the Fig 1.1. The wings consist of two essential parts. The internal wing structure, consisting of spare ribs, stringers, and the external wing, which is the skin. Ribs give the shape to the wing section, 
support the skin (prevent buckling), Aerodynamic forces not only bend the wing, they also twist it.

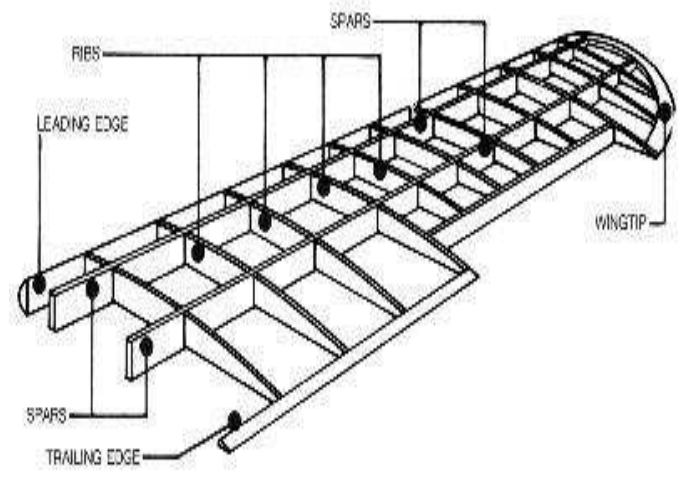

Fig -3: Internal structure of the wing

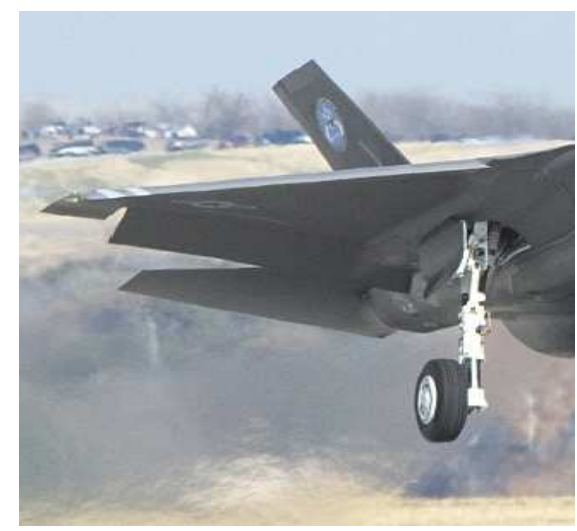

Fig -1: Landing gear cutout

\subsection{Wing loads and other loads}

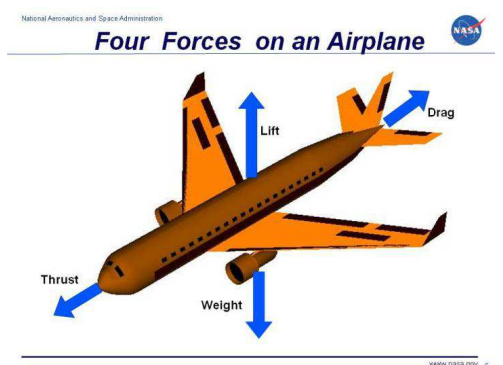

Fig -4: Four Force of Airplane

A wing produces lift as a result of unequal pressures on its top and bottom surfaces. This creates a shear force and a bending moment, both of which are at their highest values at the point where the wing meets the fuselage. The structure at this point needs to be very strong, to resist the loads and moments, but also quite stiff, to reduce wing bending.

But the main force caused by the landing gear is an upward shock during landing. For this, shock absorbers are present, absorbing the landing energy and thus reducing the force done on the structure. The extra Work generated during a hard landing results in a very large increase in the force on the structure. This is why the absorbers are designed with a safety margin by taking into account a vertical speed 1.25 times higher than the maximum vertical speed during landing.

\section{OBJECTIVES}

\subsection{Objective}

1 Ensure the safety of the structure.

2 Damage tolerance design of the wing structure.

3 Conducting stress analysis of panel consisting of stress concentration region, where fatigue crack can get initiated.

Damage tolerance evaluation of the stiffened panel, to verify the crack arrest capability of the stiffener nearer to cut out.

\subsection{Steps involved and software used}

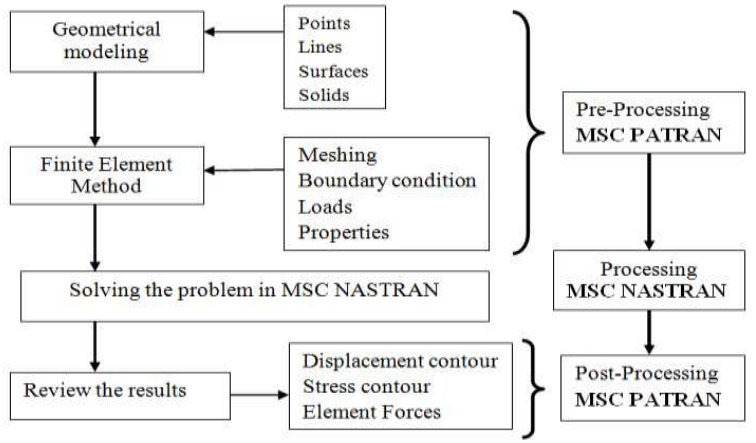

Fig -5: Steps involved and software used

\section{CONCEPTUAL DESIGN}

The conceptual design of the landing gear cutout is modeled using commercially available modeling software CATIA V5. Model showing the landing gear cutout, which has skin, cutout, holes, stiffener, and stiffener web. By using the NASTRAN and PATRAN software, meshing is done, and loads and boundary conditions are applied. Analysis is done, and hence we get the maximum stress located point. .

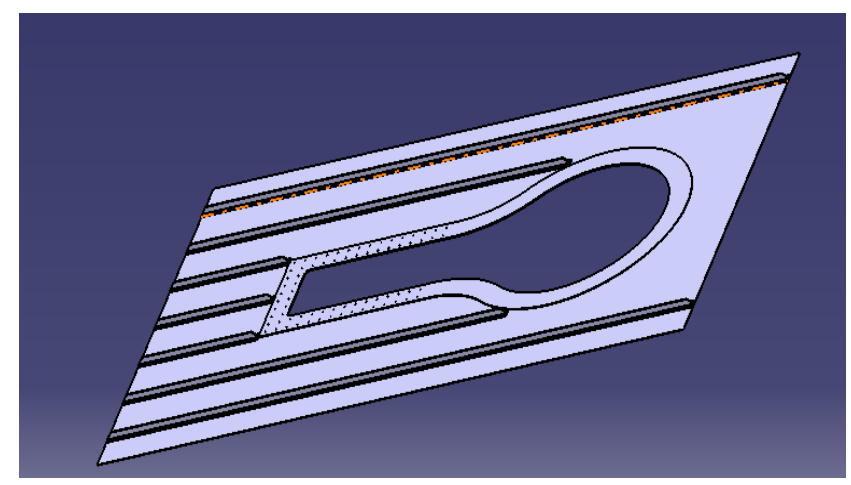

Fig -6: CAD Model of the landing gear opening cutout 


\subsection{FINET ELEMENT MODELING \& ANALYSIS}

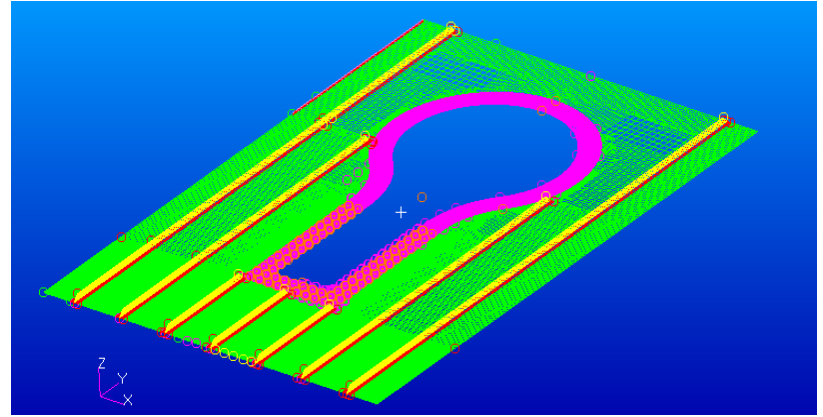

Fig -7: Meshed model

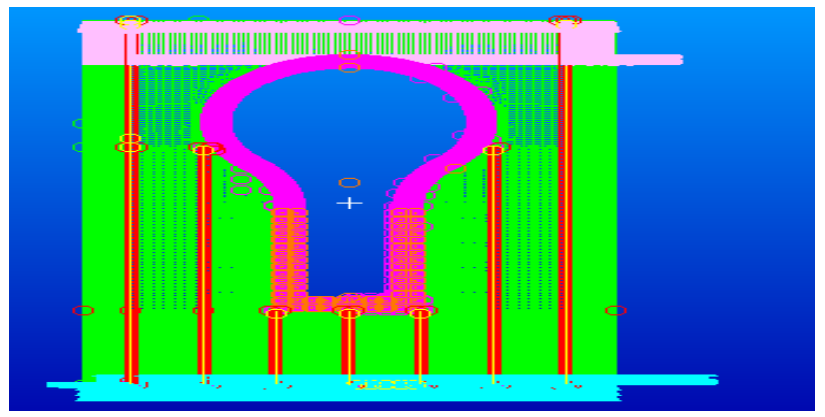

Fig -8: Meshed model(2)

Assigning boundary conditions in the static structural analysis involves constraining six degrees of freedom system (Three Translation and Three Rotation) , and uniformly distributed load of $10.23 \mathrm{KN}$ is applied to the full length of $1800 \mathrm{~mm}$. Different thicknesses are given for different group that is $5 \mathrm{~mm}, 4 \mathrm{~mm}$ and $2 \mathrm{~mm}$ $5 \mathrm{~mm}$, respectively for cutout, stiffener and skin, holes. Material properties are applied. Stress analysis is done in the Software MSC NASTRAN/PATRAN. By conducting the stress analysis we will find that

the maximum tensile stresses acting in the stiffened panel is at the rivet hole location in the panel. And cracks will always initiate from the location of the maximum tensile stress.

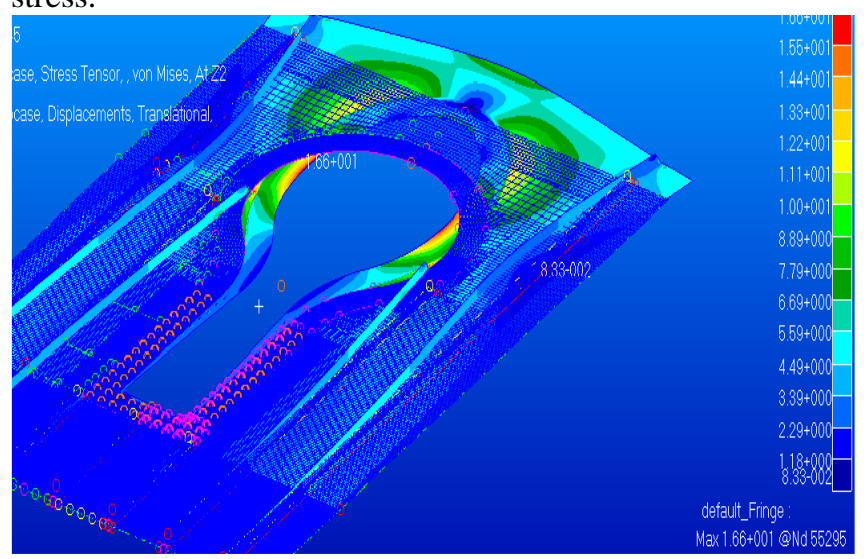

Fig -9: Maximum stress location in the stiffened panel cutout
We get the maximum stress location point , and maximum stress $1.66+001 \mathrm{~kg} / \mathrm{mm}$. The validation of the analytical method is done by calculating the SIF of plate with a crack problem analytically and comparing it with the theoretical SIF. Once we get the maximum stress concentration region, we can say that crack will get initiated from that maximum stress location and propagate perpendicular to the applied load direction. So more fine meshing is done in the region where the stress is maximum up to the stiffener, because this is the expected region of the crack initiation and propagation. Stress and displacement

Analysis of the finite element model of a stiffened panel with a crack is done.

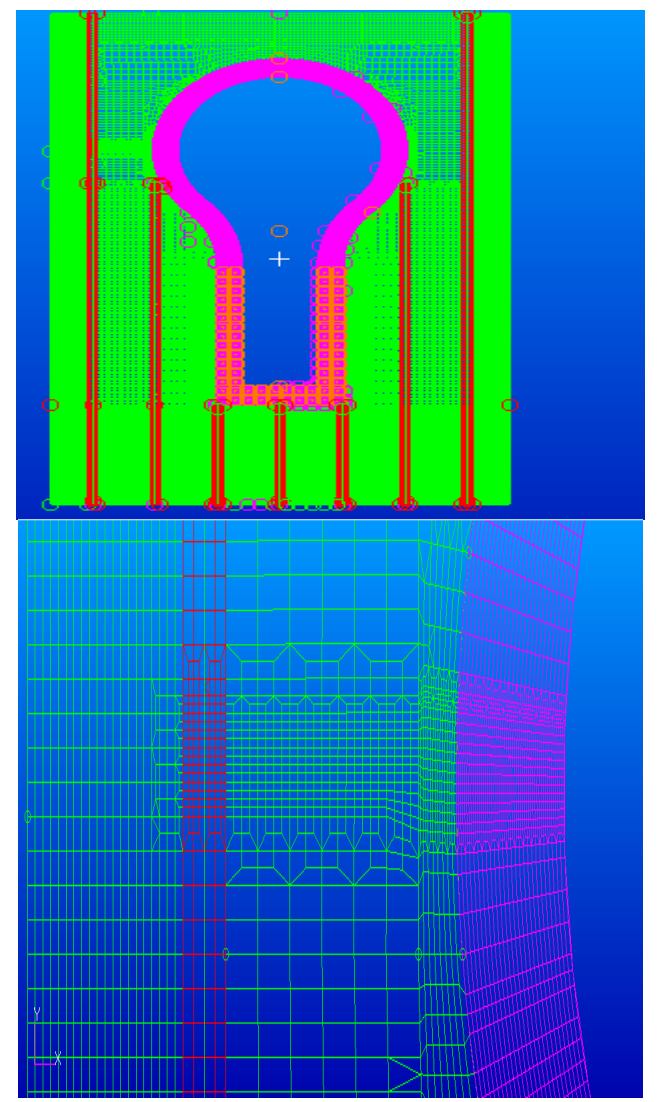

Fig -10: Stiffened panel with fine meshing at the maximum stress region

Calculation of stress intensity factor using Modified Virtual Crack Closure Integral (MVCCI) method is done for each and every crack length starting from the maximum stress obtained at the rivet hole upto the stiffeners. Here below calculation of SIF for a crack length of $92 \mathrm{~mm}$ is shown. 


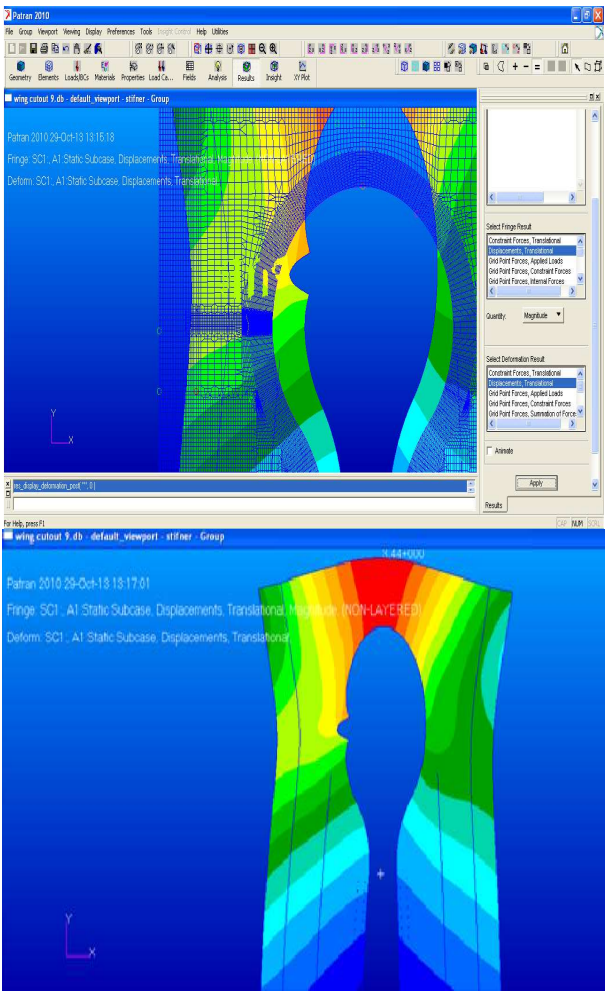

Fig -1: Displacements in the stiffened panel with a crack

\section{3 calculation of SIF for a crack length of $92 \mathrm{~mm}$}

For a crack length "a" $=92 \mathrm{~mm}$ and thickness displacement of the node near the crack tip is where node no $=124232$ its displacement is 1.637059 node no $=125625$ its displacement is 1.451928

Difference of these two is $\Delta v=0.185131$

force at the crack tip is $\mathrm{F}=$

Where $\mathrm{F} 1=547.2903 \mathrm{~N}$

$\mathrm{F} 2=712.8049 \mathrm{~N}$

$\mathrm{F}=547.2903+712.8049=1260.0952 \mathrm{~N}$

1.9228646

Length of the element near the crack tip is $\Delta \mathrm{a}=$

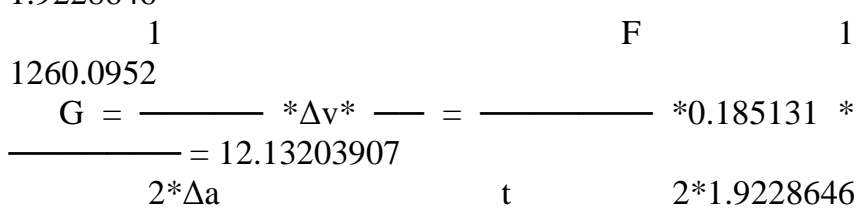

5

Where $\mathrm{k}=291.417 \mathrm{~kg} / \mathrm{mm}$

Then converting it $=90.403 \mathrm{Mpa}$

Similarly stress intensity factor for different crack length is calculated and is given in the table below.

Table -1: Stress intensity factor for different crack length

\begin{tabular}{|c|c|c|c|c|c|c|c|c|c|c|}
\hline \multirow{2}{*}{$\begin{array}{l}\text { Crack } \\
\text { length ' } \mathrm{a} \text {, } \\
\text { from hole } \\
\text { edge in } \\
\mathrm{mm}\end{array}$} & \multirow{2}{*}{$\begin{array}{l}\text { Thick } \\
\text { ness } \\
\text { ' } \mathrm{t} \text { ' in } \\
\mathrm{mm}\end{array}$} & \multirow{2}{*}{$\begin{array}{l}\text { Element } \\
\text { length 'c' in } \\
\mathrm{mm}\end{array}$} & \multicolumn{3}{|c|}{$\begin{array}{l}\text { Node displacement } \\
\text { in } \mathrm{mm}\end{array}$} & \multicolumn{3}{|c|}{ Force ' $\mathrm{F}$ ' in $\mathrm{N}$} & \multirow{2}{*}{\begin{tabular}{|l} 
Strain \\
energy \\
release \\
rate \\
' $\mathrm{G}$ ' in \\
$\mathrm{mm}$
\end{tabular}} & \multirow{2}{*}{$\begin{array}{l}\text { SIF } \\
\text { ' } \mathrm{K} \text { ' in } \\
\text { Mpa }\end{array}$} \\
\hline & & & 1 & 2 & & F1 & \begin{tabular}{|l} 
F2 \\
\end{tabular} & $\mathrm{F}$ & & \\
\hline 7.69 & 5 & 1.922834 & 1.45 & 1.39 & 0.059 & 188.1 & 217.4 & 405.5 & 1.2466 & 28.97 \\
\hline 46.15 & 5 & 1.922803 & 1.50 & 1.37 & 0.129 & 385.6 & 493.6 & 879.3 & 5.9240 & \begin{tabular}{|l|l|}
63.17 \\
\end{tabular} \\
\hline 69.23 & 5 & 1.922867 & 1.55 & 1.40 & 0.154 & 456.5 & 596.7 & 1053.2 & 8.4692 & 75.53 \\
\hline 92.30 & 5 & 1.922864 & 1.63 & 1.45 & 0.185 & \begin{tabular}{|l|l}
547.2 \\
\end{tabular} & 712.8 & 1260.0 & 12.132 & 90.40 \\
\hline 117.86 & 2 & 2.248915 & \begin{tabular}{|l}
1.78 \\
\end{tabular} & 1.52 & 0.260 & 354.0 & 466.8 & 820.12 & 23.747 & 126.48 \\
\hline 150.68 & 2 & \begin{tabular}{|l|l|}
7.48474 \\
\end{tabular} & 1.98 & 1.51 & 0.470 & \begin{tabular}{|l|l|}
757.8 \\
\end{tabular} & 634.5 & 1392.34 & 21.871 & 121.38 \\
\hline 210.52 & 2 & \begin{tabular}{|l|}
7.48474 \\
\end{tabular} & 2.15 & 1.68 & 0.467 & \begin{tabular}{|l|l|}
752.6 \\
\end{tabular} & 632.5 & 1385.23 & 21.612 & 120.66 \\
\hline 240.22 & 2 & \begin{tabular}{|l|}
7.48474 \\
\end{tabular} & 2.24 & \begin{tabular}{|l|l|}
1.77 \\
\end{tabular} & 0.463 & \begin{tabular}{|l|l|}
744.4 \\
\end{tabular} & 627.6 & 1371.86 & 21.236 & 119.60 \\
\hline 270.37 & 2 & 7.48468 & 2.32 & 1.87 & 0.451 & 612.3 & 724.0 & 1336.43 & 20.175 & 116.58 \\
\hline 300.30 & 2 & 7.48472 & 2.39 & 1.97 & 0.419 & \begin{tabular}{|l|l|}
659.0 \\
\end{tabular} & 568.4 & 1227.40 & 17.203 & 107.65 \\
\hline
\end{tabular}

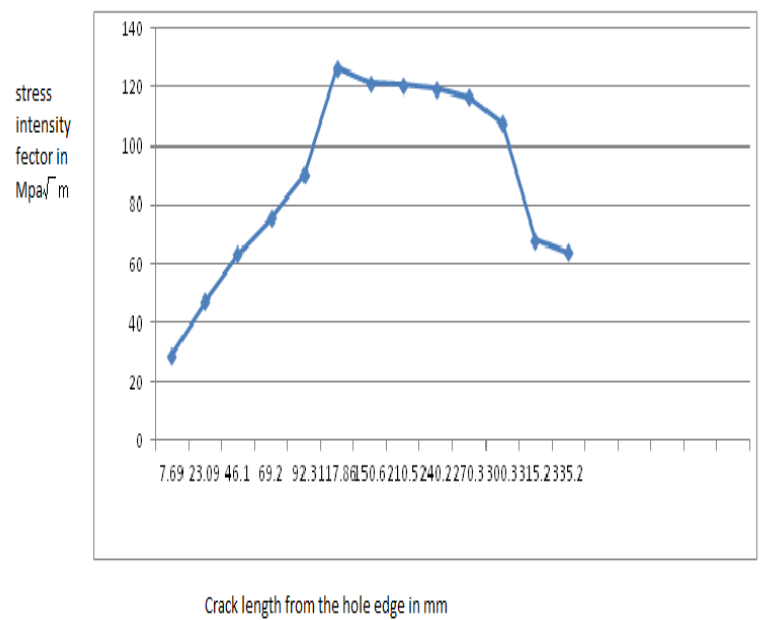

Chart -1: Variation of SIF for different crack lengths

\section{CONCLUSIONS}

The main objective of the present study is the damage tolerance evaluation of wing in presence of large landing gear cutout through stress analysis using FEM. The prediction is necessary because one should always know the time when the crack in the structure becomes critical. If one fails to find this then there may be a sudden catastrophic failure of the structure. This may even lead to the loss of life. Here in this study we first carry out the stress analysis of a stiffened panel with landing gear opening cutout of a transport aircraft wing. Stress analysis is done in the software MSC NASTRAN/PATRAN. By conducting the stress analysis we will find that the maximum tensile stresses acting in the stiffened panel is at the rivet hole location in the panel. And cracks will always initiate from the location of the maximum tensile stress. The validation of the analytical method is done by calculating the SIF of plate with a crack problem analytically and comparing it with the theoretical SIF. And we find that SIF obtained from both analytical and theoretical method are same. By this we can conclude that the FEA software used for analysis is valid. Hence the damage tolerance can be done, by using stiffeners in the wing, 
so that, the crack gets arrested as it reaches the stiffener and the stress reduces.

\section{ACKNOWLEDGEMENT}

I wish to thank to our HOD, Dr.N G Subramanya Udupa, Department of Mechanical Engineering (PG) at Nagarjuna college Of Engineering \& Technology, Bangalore, for guiding and encouraging me throughout the work. I would like to extend many thanks to professor venkate gowda c Department of Mechanical Engineering (PG), Nagarjuna college Of Engineering \& Technology, Bangalore, for supporting during course.

\section{REFERENCES}

[1]. Boris G. Nesterenko, "Analytically experimental study of damage tolerance of aircraft structures", Moscow Institute of Physics and Technology (State University), Department of Aerodynamics and Flight Engineering, Russia, 2002.

[2]. Grigory I. Nesterenko, "Service life of airplane structures", Central Aerohydrodynamic Institute (TsAGI), Russia, 2002.

[3]. A Rama Chandra Murthy, G S Palani Nagesh R Iyer, "Damage tolerant evaluation of cracked stiffened panels under fatigue loading", Sadhana Vol. 37, Part 1, February 2012, pp. 171-186.

[4]. S. M. Beden et al "Review of Fatigue Crack Propagation Models for Metallic

Components" European Journal of Scientific Research, ISSN 1450-216X Vol.28 No.3 (2009), pp.364-397.

[5]. Jarkko Tikka and Patria, "Fatigue life evaluation of critical locations in aircraft

structures using virtual fatigue test", 2002.

[6]. J. C. Newman, Jr., "Crack growth predictions in aluminium and titanium alloys under aircraft load spectra", Department of Aerospace Engineering, Mississippi State University,

Mississippi State, MS, USA .

[7]. S.M.O. Tavares et al, "Stress intensity factors by numerical evaluation in cracked

structures", Department of Mechanical Engineering and Industrial Management.

[8]. J. C. Newman, Jr, "Advances in fatigue and fracture mechanics analyses for aircraft

structures", Mechanics and Durability Branch, NASA Langley Research Center, Hampton,

VA, USA.

[9]. A. Brot et al., "The damage-tolerance behaviour of integrally stiffened metallic

structures", Israel Annual Conference on Aerospace Sciences, 2008

[10]. Park Jeong Kyu et al., "Finite Element Method analysis and Life Estimation of

aircraft structure Fatigue/Fracture Critical Location", Korea Aerospace Industries, Sacheon

City, South Korea, 2001.

[11]. Michael Chung Yung Niu, "Airframe Structural Design”, Conmilit press Ltd, 1989.

\section{BIOGRAPHY}

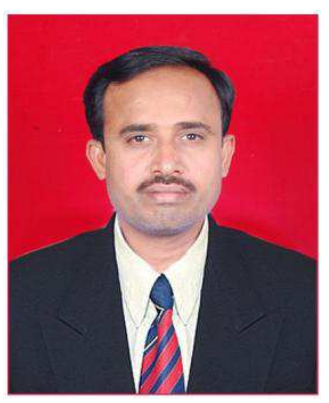

Dr. Rajanna.S, MIE, has proven track records of valuable services in teaching and research for 18 years at various Institutions which are affiliated to Bangalore University and VTU University. Successfully operated funded research projects, guided BE and M.Tech students published 11 Technical papers in National and International Journals. Presented 26 Technical papers in National and International Conferences and attended 15 workshops, seminars and staff development programmes in various Institutions and have been a member of 05 Professional bodies like IIW, IEI etc. 